\title{
We're Forever Grateful, Dear Big Sister
}

\author{
Brynjulf Stige ${ }^{12 *}$, Katrina McFerran ${ }^{3}$, Susan Hadley ${ }^{4}$ \\ 1 University of Bergen, Norway \\ 2 Uni Research, Norway \\ 3 University of Melbourne, Australia \\ 4 Slippery Rock University, PA, USA \\ *brynjulf.stige@uib.no
}

Published: 1 November 2017

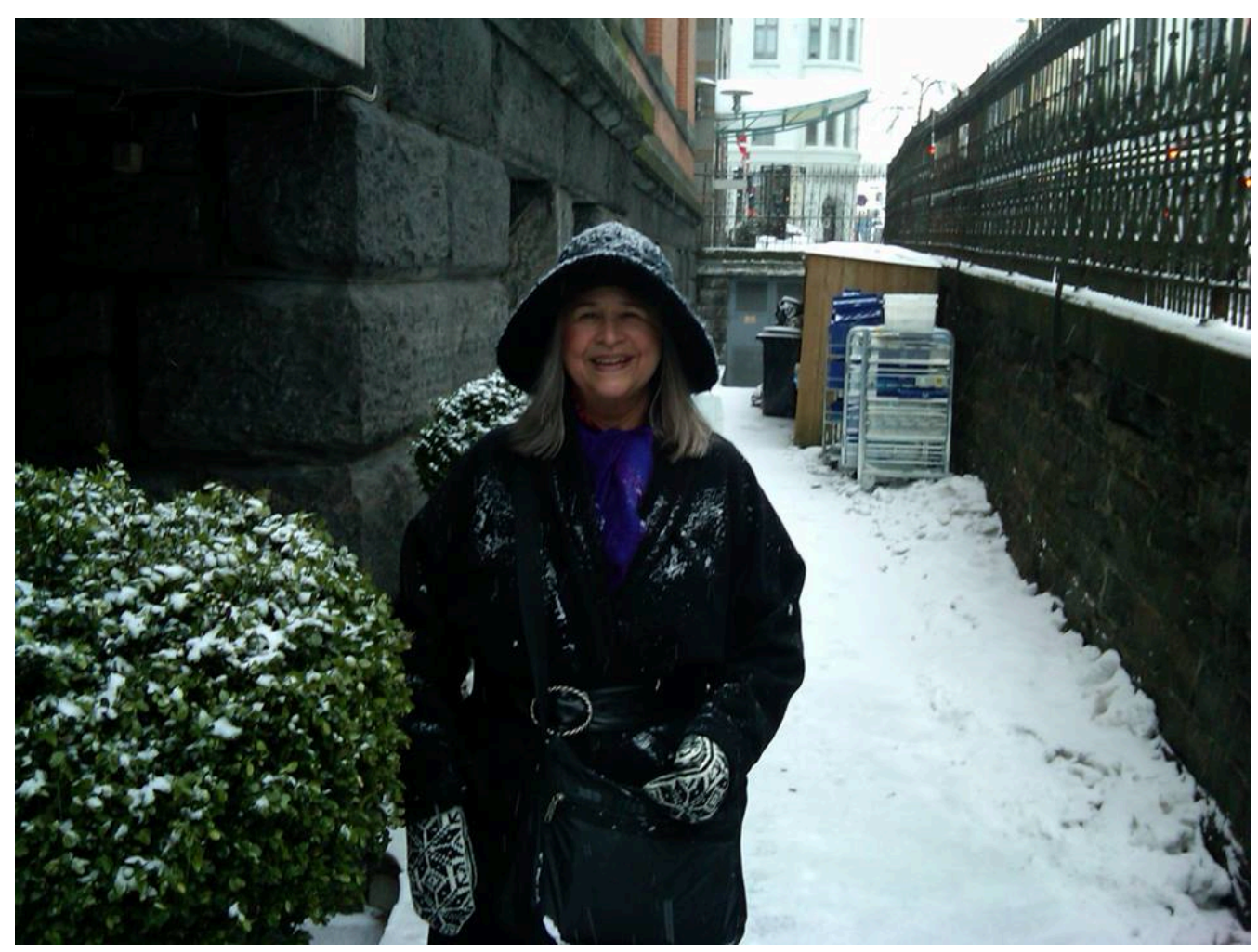

One of the founders of Voices, Dr. Carolyn Kenny, a dear friend and mentor to so many music therapists, passed away on October $15^{\text {th }}$, after a period of ill health. It is a great loss for friends and family, for music therapy, and for a much broader community.

Already in the 1980s, Carolyn authored remarkable books like The Mythic Artery and The Field of Play. Nobody else wrote anything similar at the time. She sensitized us to culture, context, and systems, as well as to myths, magic, and spirituality. She was humble, yet brave. She was sophisticated, yet amenable. She continuously sought for a synthesis between traditional human wisdom and contemporary knowledge and practice. She forcefully argued for the significance of social-cultural participation, and against any kind of professional and scientific "isolationism."

In The Field of Play, she argued: 
... we bring a unique set of conditions to interplay with society and culture. This position carries a responsibility for deep examination of the influence we may have on the cultureat-large.

During the 1990s she developed further her contextualized understanding and advocated for the social responsibility of the music therapy researcher. Gradually she also expanded her approach to incorporate a more anthropological focus, examining the role of arts in the revitalization of traditional societies.

Who would be more qualified than Carolyn to help build a world forum that could foster critical thinking, nurture the profile of music therapy as an inclusive global enterprise, and sustain exchange between various cultures and traditions? This was the question Brynjulf asked himself in 1999 when he, through dialogue with Lisa Summer, had developed an inkling; a rough idea which eventually would become the forum that we know as Voices. The fact that we managed to establish the forum two years later was very much due to Carolyn's positive response, and to her skills, vision, and endurance.

Brynjulf had the pleasure of developing Voices with Carolyn for 15 years, from 1999 to 2013. It was one of the best and most meaningful experiences you could think of, and a relationship of great mutuality. Obviously, Carolyn was the senior. She was the wise woman who had travelled the world but who was also very rooted in her own traditions, including those of the Eagle Clan of the Haida Nation, which had adopted her. There was so much to learn from Carolyn, and Brynjulf felt very honoured when, after a period of hard collaborative work, she started to call him Little Brother. She even allowed him to call her Big Sister, and what more could you ask for?

When Carolyn decided to end her tenure at Voices, Brynjulf approached Susan to become one of the new co-editors. However, Susan was very reluctant to move into the role. One reason was because of her sense of reverence to Carolyn's legacy. While contemplating what it was that she could contribute in this role, it was Carolyn who convinced her that it was a good fit through several meaningful conversations. It was Carolyn's encouragement and belief and her wise mentoring over the next four years that helped make the transition to the new editorial team a smooth one.

While we, as editors, hold her up as a wise Big Sister, her non-hierarchical approach in her relationships allowed us to feel loved and valued. One of our editors, Melody Schwantes, fondly remembers Carolyn's impact on her at a crossroad in her professional journey, saying that Carolyn's reflection on one of her publications functioned as "an academic hug." Melody said that in that moment she "felt like someone had faith in me that I didn't have in myself." It was because of Carolyn's loving spirit that she was able to continue on her path.

This embodied, intimate and personal approach was also core to Katrina's experience of relationship with Carolyn, and likely many people around the globe. Every interaction involved a discussion about family, about friends, about wellbeing and about the people and things that we cared about. As an editor of Voices, this was apparent in the way that Carolyn would reach out personally to reviewers and writers, naturally beginning a dialogue between all those involved in order to achieve a beautiful outcome through the expression of the piece. She often shared her opinion, frequently offered warm guidance, but never demanded a particular outcome or attempted to skew a dialogue to her preferred direction. As a reviewer with Voices from the early 2000s, Katrina was moved by this personal approach, which was so different to her experiences of other journals. The way Carolyn lived her values without compromise to the dominant 'scientific' approach was a powerful model of how to be in a world that seemed to demand a less subjective and more detached approach. After Carolyn completed her time as Editor, it became necessary to articulate and honour these values more clearly, and much of Carolyn's influence on the forum is now repeated over and over as we bring new editors, reviewers, writers, creators and readers into our community. 
Five weeks before she left this earth, Carolyn shared with Susan her sadness that she could not complete a chapter for an upcoming book exploring themes of colonization, themes deeply infused her in writings. In that chapter she was going to explore what she refers to as "radical mutuality," which she describes as necessary in order to connect deeply (spiritually) with those with whom we work. She described radical mutuality in the following way:

We have to put aside various aspects of our own identity, like "position", or "healthy" to engage fully. How do we colonize ourselves intra personally as Music Therapists so that this deep connection cannot be realized? Then how do we subsequently colonize our patients and clients?

This type of engagement flies in the face of most Western notions of a therapist's "place" in the therapeutic encounter. We learn in our training that the therapist is the healthy one, knows the best tools to involve the patient, has been highly trained and has many more resources than the client. The therapist is in a community (culture) of practitioners who share similar competencies. And the list goes on and on.

How can we put aside such a position of privilege to become free enough to experience a deep sense of wonder with our patients and clients, the wonder that brings transformation and change? How can we really "play" when burdened with the many complexities of our own identity?

We miss Carolyn, and we want to go back to the power, poetry, and playfulness of her writing. Just read and listen to the titles of some of the columns she wrote for Voices the first few years: "The Dilemma of More or Less", "Yearning for Beautiful Ideas", "Get Me Back to the Music", "Through the Sound", "Snowball the Dancing Cockatoo" and "Samba! Samba!". We can go back to Carolyn's work in order to learn more about how to move forward.

In a recent book edited by Joseph Moreno, The Lives of Music Therapists, Carolyn describes how she developed a deep healing relationship to music as a young person, and how she initially rejected the idea of music therapy when she first heard about it: "because it seemed that this "profession" did not have much in common with my sense of what music therapy was or could be." As the current co-editors of Voices, we feel that our sense of what music therapy is and could be has expanded enormously over the years. Carolyn has played no small part in that process. Dear Big Sister: Please hear our message of appreciation and affection. We're forever grateful.

I know what I know only

Because of the kindness of others and the gifts

bestowed upon me By the Creator

For this I give thanks and of

course, always, to the land. This is

why I dance and sing.

All my relations!

C.B. Kenny, 1997 